\title{
Ignacio Ellacuría, filósofo cristiano. Reflexión filosófico-teológica sobre la inexorable acción de cargar con la realidad
}

\author{
Lorena Zuchel \\ UNIVERSIDAD TÉCNICA FEDERICO SANTA MARÍA \\ VALPARAÍSO, CHILE \\ lzuchel@gmail.com
}

Resumen: El presente artículo expone propuestas ético-biológicas de I. Ellacuría: cargar, hacerse cargo y encargarse de la realidad, que forman parte de una reflexión filosófica en diálogo con X. Zubiri. Se les sumará la reflexión teológica de Sobrino de dejarse cargar por la realidad, que emana del diálogo con Ellacuría sobre la verdad de los pueblos latinoamericanos en construcción de un Reino, Civilización o Vida nuevos. Será un recorrido por las tesis que muestran el interés radical por la Verdad, cuestión que atraviesa ejes filosóficos y teológicos, en el caso de Ellacuría, pero sobre todo con sentido ético, que permitiría la concreción real de posibilidades humanas, que por ser humanas, sobrepasan racionalidades que limitan los desafíos vitales de liberación propios del pensamiento ellacuriano.

Palabras clave: Filosofía, Teología, Política, Ética, Sujeto de la historia, Realidad, Verdad.

Abstract: This article presents ethical and biological proposals of I. Ellacuría: to take responsibility and give account of reality. The latter part of a theological is discussion with X. Zubiri. In addition, the text includes the theological reflection put forward by Sobrino letting oneself flow with reality. This emanates from the dialogue with Ellacuría about the truth of Latin-American peoples regarding the construction of a new Kingdom, Civilization or Life. We will review those theses that show the radical interest for Truth, that, in Ellacurías case, cuts across philosophical and theological key concepts. It relates to an ethical sense that would allow the concrete realization of human possibilities which, precisely due to its human nature, transcend rationalities that might hinder the vital liberation challenges dear to ellacurian thought.

Keywords: Philosophy, Theology, Politics, Ethics, Historical Subject, Reality, Truth. 


\section{INTRODUCCIÓN}

Poco se conoce a Ignacio Ellacuría (1930-1989) como filósofo de la liberación; es en su faceta de teólogo jesuita, o como discípulo de Xavier Zubiri como principalmente se le recuerda. Quizá su precipitada muerte (asesinado el 16 de noviembre de 1989 a los 59 años, junto a cinco sacerdotes jesuitas, a una trabajadora del hogar y a la hija de esta) lo dio a conocer en América Latina, que ya llevaba otras tantas vidas cercenadas ${ }^{1}$. Pero habrá que decir también, que son esas décadas -en las que tantos teólogos alzan palabras por los oprimidos de las regiones más pobres- las que vuelven la filosofía latinoamericana fértil y auténtica, en un proceso de autoemancipación y liberación de las naciones y de sus gentes, que vuelven el largo trascurso histórico de esclavitudes e independencias, momento culmen en el que la propia filosofía ellacuriana se destaca, en intercomunicación liberadora con pensamientos foráneos, y en intercomunión con otras disciplinas, como la literatura, el arte, la pedagogía, la teología. Por ello, es necesario entender a Ellacuría como aquel pensador en el que entreveran distintos espacios del conocimiento, y en especial, la filosofía y la teología, con un evidente trasfondo ignaciano, que hacen de su existencia, discernimiento sobre la vida, muerte y resurrección de Jesús de Nazareth, como de sus opciones por la liberación de los pobres de la tierra² ${ }^{2}$.

El 12 de marzo de 1977 es asesinado el sacerdote jesuita, párroco de Aguilares, Rutilio Grande García; el 11 de mayo de 1977, es asesinado el párroco de la Colonia Miramonte de San Salvador, el padre Alfonso Navarro Oviedo; el 28 de noviembre de 1978 es asesinado el sacerdote Ernesto Barrera Motto, que realizaba labores de pastoral obrera en Ciudad Delgado; el 20 de enero de 1979, el sacerdote Octavio Ortiz es asesinado en una casa de retiros en San Antonio Abad, junto a 4 jóvenes laicos que participaban de un retiro vocacional; el 20 de junio de 1979 es asesinado en santa Tecla el sacerdote Rafael Palacios; el 4 de agosto de 1979 es asesinado el sacerdote Alirio Napoleón Macías; el 24 de marzo de 1980 es asesinado el Arzobispo metropolitano de San Salvador, monseñor Óscar Romero; en marzo de 1989, es asesinado el sacerdote jesuita, columnista de El Diario de Hoy, Francisco Peccorini Letona; el 2 de diciembre de 1980, las religiosas norteamericanas de Maryknoll, Ita Ford, Maura Clarke, Dorothy Kazel y Jean Donovan, son violadas y asesinadas.

2 Cf., J. Sobrino, “El Ellacuría olvidado». Lo que no se puede dilapidar”, en J.A. Senent de Frutos, J. Mora Galiana, Ignacio Ellacuría 20 años después. Actas del Congreso Internacional (Instituto Andaluz de Administración Pública, Sevilla 2009) 319-342. 
A continuación, se trabajarán estas dos influencias en Ellacuría, la filosofía y la teología, para mostrar cómo su pensamiento no es dicotómico, y están unidos por unos mismos desafíos y exigencias; cómo su filosofía queda incompleta si se le entiende divorciada de algunas formulaciones propiamente cristianas como la de la praxis evangélica de Jesús de Nazareth. Acudiremos, para ello, a dos autores que encausarán nuestras formulaciones, y que estuvieron muy presentes en su vida: El filósofo Xavier Zubiri, quien fue su maestro, pero también una persona que se dejó enseñar por aquel discípulo inquieto; y Jon Sobrino, compañero de congregación religiosa, de ciudad ${ }^{3}$, y cómplice en la causa de la liberación.

\section{EN DIÁLOGO CON XAVIER ZUBIRI}

El término Hacerse cargo de la Realidad es un término propiamente zubiriano. En su libro Estructura dinámica de la realidad, Xavier Zubiri expresa con él la evolución de la vida humana dentro de la escala zoológica, y manifiesta lo que constituye al ser humano en animal de realidades. Para Zubiri, hacerse cargo de la realidad constituye un cierto dinamismo de suidad, en donde retoma la relación entre inteligencia y sentido, pues involucra un estímulo de hiperformalización que destaca en el hombre, animal de realidades, la posibilidad de continuar con la especie de una forma original y fundamental, al convertir, desde el nacimiento, lo meramente estimúlico (conexión animal de estímulo y respuesta) del medio en mundo. Y dice:

"[Esto significa] primero que el hombre es radical y constitutivamente una esencia abierta. Abierta precisamente al carácter de realidad de las cosas. No está pendiente de la cualidad de los estímulos, sino que está en principio, por lo menos, abierta a la realidad de las cosas. Y, ni qué decir tiene, abierta en primera línea a su propia realidad. No da sus respuestas únicamente en virtud de la talidad de las suscitaciones, sino que da esas respuestas haciéndose cargo de la realidad, y de lo que a él realmente le va a acontecer. Estructuralmente, el hombre -digo- es un animal de realidades"4.

3 Los dos nacidos en Bilbao, ciudad del País Vasco, comunidad autónoma de España, y entonces hermanados por una historia común su pueblo y nación; y avenidos también por el deporte, el Athletic de Bilbao, club de fútbol de su ciudad natal que les permitía compartir momentos de mucha cotidianidad.

4 X. Zubiri, Estructura dinámica de la realidad (Alianza Editorial y Fundación Xavier Zubiri, Madrid 1989) 206. 
Ser animal de realidades es, según Zubiri, una responsabilidad enorme para el ser humano, para el viviente humano que no podrá vivir si no está abierto intelectivamente a la realidad ${ }^{5}$, pues más allá de ser un sustantivo de suyo se vuelve dueño de las acciones que ejecuta cotidianamente en la realidad; el viviente humano no es simplemente algo que "funciona" en la vida (en función de la vida), sino que es algo para lo que la vida está funcionando (la vida en función de la realidad). De esta forma, pasa de ser, el viviente humano, un de suyo a un ser suyo, vale decir, ser una realidad suya. A esta forma de realidad Zubiri le llama persona. Lo que quiere decir que estructuralmente es el ser humano un animal de realidades, y modalmente es persona ${ }^{6}$.

En la identificación de la persona, tal como desde la avanzada modernidad se ha reiterado, Zubiri descarta la idea de unidad e identidad cerrada consigo misma, y considera todas aquellas realidades que dificultan la aprehensión de la individualidad, precisamente por su condición siempre abierta. La persona es aquella esencia abierta, y abierta principalmente "a su propia realidad, y en ella a la realidad de las demás cosas precisamente en tanto que reales" realidad, y en el acto tiene que hacerse cargo de ella. Ya nos decía Ortega y Gasset, con quien este filósofo dialoga, que tener vida no es acto vacío, como tampoco es recibir toda nuestra existencia y comportamientos ya grabados, sino que esta se resuelve en trabajo y creación:

"Esa vida que nos es dada, nos es dada vacía y el hombre tiene que írsela llenando, ocupándola. Estas son nuestras ocupaciones. Esto no acontece con la piedra, la planta, el animal. A ellos les es dado su ser ya prefijado y resuelto. A la piedra, cuando empieza a ser no le es dada solo su existencia, sino que le es prefijado de antemano su comportamiento -a saber, pesar, gravitar hacia el centro de la tierra. Parejamente al animal le es dado el repertorio de su conducta, que va,

5 Zubiri dirá más adelante que una especie de idiotas es inviable, la capacidad instintiva no es suficiente para su pervivencia. X. ZuBIRI, Estructura dinámica..., 213.

6 X. Zubiri, Estructura dinámica..., 207. Agregaremos a esto que, para Zubiri, el ser humano, que en su inteligencia sentiente se hace cargo de la realidad, es, en el acto, cuando es más plenamente persona; acto personal que tiene un doble aspecto, a saber, el del acto determinado por la razón del objeto, y por otro lado, el que, en el mismo acto, constituye una manera propia de estar en la realidad; en efecto, este último aspecto es el que lo hace ser personal. Cf., X. ZuBiRI, "La dimensión histórica del ser humano", en Realitas (1973) 14.

7 X. Zubiri, "La dimensión histórica..." 14 
sin su intervención, gobernada por sus instintos. Pero al hombre le es dada la forzosidad de tener que estar haciendo siempre algo, so pena de sucumbir, mas no le es, de antemano y de una vez para siempre, presente lo que tiene que hacer. Porque lo más extraño y azorante de esa circunstancia o mundo en que tenemos que vivir consiste en que nos presenta siempre, dentro de su círculo y horizonte inexorable, una variedad de posibilidades para nuestra acción"8.

Ocuparse de las cosas del mundo pueden darnos diariamente innumerables posibilidades de acción, mas son nuestras elecciones, y las acciones que al fin efectuamos, las que van haciendo que en la realidad nuestra vida esté conectada con las cosas, esté en la realidad de las cosas y se enfrente con ellas como realidad. Dicho de otro modo: No nos queda otra que hacer algo con las cosas de este mundo, no podemos cerrar nuestros ojos y creer que en el acto estamos haciendo nada con nosotros mismos; pues algo hacemos con la venda, con la oscuridad y con los objetos y sujetos que deseamos no ver. Por tanto, no nos queda otra que elegir, y de elegirnos a nosotros mismos. Esta exigencia biológicaexistencialista que es acto primero en el ser humano fue tratada por Ellacuría del siguiente modo:

"El animal de realidades al tener que abrirse a la realidad, a lo que son 'de suyo' las cosas más allá de la pura determinación estimúlica, al tener que optar tendencialmente en un mundo de posibilidades, al enfrentarse consigo mismo y con las cosas como realidad, se constituye formalmente en realidad moral. En este sentido, el hombre no está 'por-bajo-de' algo que se le impone, sino que está 'por-encima-de' sus condicionamientos naturales. Resulta así que la posibilidad fundamental del hombre, que hace positivamente posibles todas las demás posibilidades estriba en este 'tener-que' abrirse a la realidad. Esta forzada apertura a la realidad se constituye así en principio de posibilidad de la Ética y en fundamento de toda ulterior determinación ética".

Posibilidad ética que se ha comprendido con la idea de cargar con la realidad.

8 J. Ortega y Gasset, El Hombre y la gente, en Obras completas, Vol. VII (Alianza Editorial-Revista de Occidente, Madrid 1983) 101.

9 I. Ellacuría, "Fundamentación biológica de la ética", en Revista de Estudios Centroamericanos (ECA) 369 (1979) 422. 


\section{CARGAR CON LA REALIDAD}

José Ellacuría, hermano de Ignacio, nos cuenta que un día su hermano estaba discutiendo con Zubiri sobre su filosofía esencial cuando le dice a su maestro que su pensamiento era como el de Heidegger, muy teórico, muy puro, que si no le parecía mejor darle un enfoque sociopolítico ${ }^{10}$. José explica que para Ignacio, la filosofía "debe interpretar los signos que nos permiten entender lo que ocurre e influir en los acontecimientos para hacer que la historia vaya no hacia una catástrofe, sino hacia una utopía en términos civiles, hacia el Reino de Dios en términos teológicos" ${ }^{11}$, y Zubiri hace suya estas convicciones, de tal modo que juntos deciden plasmar aquellas ideas sobre inteligencia sentiente en las máximas de hacerse cargo de la realidad, cargar con la realidad y encargarse de la realidad, dimensión noética, ética y práctica, respectivamente. Es así como en los escritos ellacurianos destaca esa síntesis teórica-práctica, o filosófico-política que bebe del pensamiento zubiriano y con Zubiri mismo, pero que a la vez es capaz de independizarse y responder a un contexto en el que la vida de Ignacio Ellacuría echa raíces: Latinoamérica.

Este esfuerzo de Ellacuría por hacer de su pensamiento un lugar de encuentro filosófico político que considere la realidad latinoamericana, no se vuelve, eso sí, respuesta regionalista, sino búsqueda apasionada por la verdad de la realidad, y por tanto de carácter universal. Por eso mismo es que tampoco se vuelve una politización del pensamiento zubiriano, sino afán de procurar el equilibrio entre teoría y práxis que todo pensamiento filosófico, precisamente por ser filosófico, debe realizar.

Bajo la idea de cargar con la realidad encontramos una clave en la definición misma de ética, del griego ethos, que, aunque menos estudiada su versión etimológica, es, según antiguos poetas griegos, la madriguera de los animales, su morada; la que más adelante se llegó a convertir en la morada del ser humano; vale decir, ethos es el lugar en donde vivimos y desenvolvemos variadas actividades. Esta comprensión de la ética nos podría ayudar a entender esto de hacer la realidad y cargar con ella; pues es el ser humano mismo el que construye el lugar en el que habita, lo transforma en función de sí mismo, y de sus propios objetivos, empero

\footnotetext{
10 Cf. J. Ellacuría, "trabajando por la paz desde la universidad" [Fecha de consulta: marzo de 2014]. Disponible en: http://www.redescristianas.net/2007/11/18/ trabajando-por-la-paz-desde-la-universidadjose-ellacuria/

11 Cf. J. Ellacuría, "trabajando por la paz...”.
} 
ocupándose también de los problemas y dificultades que pueda significar el vivir en comunidad ${ }^{12}$. En efecto, el animal de realidades, asume cargar sobre sus hombros la realidad, y la acepta sobre su propia existencia. Sobre esto nos recuerda el filósofo salvadoreño, Héctor Samour, que

"[...] se presenta éticamente como la necesidad de encargarse de la realidad para que sea lo que debe ser; que se haga con la realidad lo que se debe hacer; la realidad ha de irse realizando y esa realización le compete al hacer humano; la realidad no va a ser lo que debe ser respecto del hombre, si el animal de realidades no se encarga positivamente de ella; supone, por tanto, una praxis responsable que supera la pura estimulidad cerrada y se alza hasta la realidad abierta, dirigida a una estricta y formal realización"13.

Encargarse de la realidad quiere decir, entonces, comprender el paso de un momento noético, de intelección de una realidad biológica, a uno ético, de compromiso con el lugar que habitamos; y de este ético, que es compromiso, a otro práxico, que se vuelve momento constitutivo de acción. Y encargarse positivamente de la realidad, quiere decir, simplemente, hacer de la realidad una realidad humana; que responda a un principio de liberación y no a uno (otro ${ }^{14}$ ) de opresión y de alienación; como, igualmente, tener en cuenta que la praxis histórica no es liberadora en sí misma, sino que debe obedecer a los signos de los tiempos, pues ningún modelo de liberación es válido para todo tiempo y lugar ${ }^{15}$. Para ello, la filosofía debe relacionarse debidamente con el sujeto de la liberación, debe hacerse con y desde el sujeto. Veamos en qué consisten estas dos ideas.

12 Como ocurre con nuestras casas (permítaseme un ejemplo): las preparamos para nuestro agrado, y como nosotros, el vecino, que martilla a la hora de nuestra siesta la lata que se ha desprendido de su techumbre.

13 H. Samour, Voluntad de liberación, La filosofía de Ignacio Ellacuria (Comares, Granada 2003) 94. Este carácter humano no debe hacerse con menoscabo de la animalidad, pues ella forma parte siempre presente del ser humano; por ello Ellacuría nos invita a potenciar, a través de ella, a un ser más humano, en vez de negar que somos, al fin, también animal. "La apertura al carácter de realidad con el que se presentan los estímulos al animal humano, es lo que le va a permitir en principio ir progresando en su humanización".

14 Otro en cuando se concede que la humanidad ha posibilitado hasta ahora una realidad histórica alienante y opresiva.

15 Sobre esto ver: J. Mora Galiana, Ignacio Ellacuría, filósofo de la liberación (Nueva Utopía, Madrid 2004) 100 ss. 


\title{
3.1. A la altura de los tiempos
}

Referirnos a los signos de los tiempos, o a la altura de los tiempos, da cuenta de la edad histórica a la que nos enfrentamos; pero no solo a una edad biológica, que como con los seres humanos trae consigo inexorablemente el hecho de la muerte, sino a una edad abierta a la vida y con ella a nuevas posibilidades de empezar de nuevo o de elegir un rumbo nuevo tras claros fracasos históricos. Ante esto, Ellacuría trabaja en Filosofía de la Realidad Histórica precisamente el término zubiriano de la altura de los tiempos, con el cual se permite la posibilidad de nuevas etapas de la historia, en las que se conjugan una variedad de elementos en los nuevos sistemas operantes, que dan pie a que en determinadas edades un mismo objeto o un mismo hecho, sea evaluado de manera distinta. Lo dice de la siguiente manera:

\begin{abstract}
"Hay una edad paleolítica porque se utiliza la piedra y sus transformaciones como útil fundamental. Pero, a su vez, utilizar hoy un instrumento de piedra tiene una realidad completamente distinta, precisamente, porque tiene lugar en otra edad: puede constituirse en una acción deportiva lo que en otro tiempo fue una estricta acción de subsistencia" 16 .
\end{abstract}

De esta suerte todo lo que constituye la realidad histórica, "todo lo que vive envuelto en la realidad" ${ }^{17}$ inclusive, nos dice, el ser histórico, el cuerpo social, que se apropia del sistema propio de cada edad, de tal forma que la edad pasa a ser rasgo propio de aquella sociedad, de su figura histórica. Ahora bien, puede ser que en un momento cronológico se topen distintas realidades, con desigual procesos históricos; de ello, que los tiempos son plurales ${ }^{18}$, y por la misma razón, la historia no puede ser contada desde una sola perspectiva.

Ellacuría se abre a la posibilidad de estas distintas lecturas, como nosotros podemos entrar a reflexionar críticamente la construcción de una sola línea periódica como comprensión unilateral de la historia. Hay países y continentes enteros que no tuvieron Edad Media -por ejemplo-, lo que no quiere decir que no existían en ese tiempo. Esta apertura

16 I. Ellacuría, Filosofía de la Realidad Histórica (Trotta y Fundación Xavier Zubiri, Madrid 1991) 351.

17 I. Ellacuría, Filosofía ...353

18 I. Ellacuría, Filosofía ..., 353. 
a la pluralidad del tiempo nos abre a la aceptación de la diversidad y de la lectura y enseñanza de múltiples historias. Pues bien,

"[...] la edad coloca así a los hombres en la línea de la coetaneidad y no simplemente en la línea de la contemporaneidad. Si no fuéramos más que contemporáneos unos de otros, poco importarían el tiempo y la historia; pero, si somos coetáneos, no se trata de nada extrínseco, sino de una determinación física de lo que somos precisamente por pertenecer a una misma altura de los tiempo, que cuenta forzosamente con una figura temporal configuradora a su vez de lo que son los hombres" ${ }^{\prime \prime}$.

En efecto, el reloj biológico de los pueblos abre la posibilidad de hacer notar un nacimiento, desarrollo y muerte, pero la historia entera de la humanidad es abierta e indefinida ${ }^{20}$, por lo que Ellacuría insiste que no es esta la que acaba con las civilizaciones, sino su gente misma que no está a la altura de los tiempos. Es así como el autor insiste en que la historia, aunque antigua, no tiene por qué ser vieja (como el viejo que se prepara a la muerte), y aunque nueva, no tiene por qué ser jovial. Justamente, así como podemos encontrar a un niño sin fuerzas ni deseos de correr, reír, salir a la calle y de proyectarse, y podemos encontrar a abuelos gozando de la vida y planificando cada semana con alegría y esperanza, así también podemos encontrar pueblos y civilizaciones maduras a pesar de su corta edad, y frescos, a pesar de lo antiguos que puedan ser: "La edad histórica no sigue la pauta de la edad biológica, sino que se mide según la altura de los tiempos y la figura temporal de un sistema de posibilidad, sistema que puede ser rehecho incesantemente, puede enriquecerse o degradarse" 21 .

\subsection{Con el sujeto de liberación}

Encargarnos positivamente de ella también trae de la mano hacerlo con el sujeto y desde el sujeto, y tal como hemos agregado anteriormente, con y desde el sujeto de liberación. ¿Qué significa esto?

Primera cosa a decir. Para Ellacuría el sujeto de la historia es un sujeto histórico, y el sujeto histórico es quien se afecta históricamente por

19 I. Ellacuría, Filosofía ..., 354.

20 Cf. I. Ellacuría, Filosofía ..., 355.

21 I. Ellacuría, Filosofía ..., 355 
la historia ${ }^{22}$. Segunda cosa, ¿de qué manera los sujetos se involucran con la historia de tal modo que se afectan por ella, se sientan parte y lugar de ella? Aunque suene redundante, Ellacuría incorpora esta observación al entender la afección histórica no como una mera acumulación de acciones humanas sino como la actualización de aquellas acciones como posibilidades $^{23}$. De aquí que es central que se den las posibilidades para que se constituya un sujeto de la historia; que se den las posibilidades de formación de las personas como autores de la historia, y no como simples arrojos, en quehacer alienante, sin la actualización consciente de las posibilidades de acciones de los mismos.

Sobre las condiciones para permitirse hablar de posibilidades históricas, Ellacuría nos dice que primero debe haber posibilidades en la realidad, es decir, que lo posible se dé como un hecho en la realidad, y no tan solo como una contradicción metafísica, abstracta. En segundo lugar, que lo posible no conlleve una configuración fija; y aunque así lo sea -insiste, Ellacuría- que esto no quitaría el hecho de la novedad de los procesos lineales evolutivos: "No solo el árbol y el fruto son una novedad respecto de la semilla, sino sobre todo un paso evolutivo sobre el anterior [...]. Las teorías de Darwin y Lamarck pueden ilustrarnos al respecto" 24 . Pero aquí, al margen de la novedad dada en la realidad-que podría ser incluso configurada desde la no dependencia de un sujeto intramundano-, es menester poner el acento en la novedad creativa que se puede dar solo insistiendo en una cierta anticipación del futuro, como requisito previo. Sobre esto nos dice el autor que:

"futuro es aquello que es posible sin estar pre-dado (no futurible), de modo que es realizable pero a modo de creación. La creación misma de posibilidades, el hacer un poder, es una forma suprema de creación humana. No solo se llega creativamente a un futuro que es estrictamente tal, sino que se llega a crear poderes nuevos para futuros nuevos" 25 .

Esto no obsta para que las realidades posean sus propias condiciones posibilitantes, y es más, son estas condiciones las que dan una eficacia

22 I. Ellacuría, "El sujeto de la historia", en Cursos Universitarios (UCA Editores, San Salvador 2009) 320.

23 Cf. I. Ellacuría, Filosofía ..., 420.

24 I. Ellacuría, "El sujeto...” 311.

25 I. Ellacuría, “El sujeto...” 313. 
real y material en la historia, las que podrán limitar y demorar su materialización, pero de las que dependerá su realización real, ya no como necesidades puramente naturales o imaginadas ${ }^{26}$.

Para Ellacuría era central mostrar a las personas de El Salvador, universitarias, pobladoras, que la historia no estaba preescrita, y que con ellos podía direccionarse hacia un futuro más humano; por eso, que las mínimas posibilidades existentes debían ser apropiadas políticamente para hacerse cargo de ella. La cuestión de las posibilidades no es nada fácil de considerar, sobre todo cuando la realidad material muestra un entramado de coerciones que impiden llevar la vida con una verdadera capacidad de elección; sin embargo, Ellacuría vio en los pobres de América Latina, a los que llamaba mayorías populares, sujetos históricos que todo cuanto puedan trocar y aprehender es liberador para ellos mismos y para la historia, ya que (parafraseando la idea heideggeriana que él mismo utilizó en otro momento) la nada y no el ser había sido quien golpeara insistentemente sus puertas ${ }^{27}$, y desde ahí, el futuro que soñaran traería ser, realidad con sentido, llevada hacia adelante desde sus más profundas experiencias de olvido.

\subsection{Desde una triple definición de filosofía e inteligencia}

Hasta aquí nos hemos aproximado a una comprensión de las posibilidades históricas que nos enseñarían el siguiente desafío ético: "aprehender la realidad y enfrentarse con ella”28. Empero estas comprensiones, como ya hemos sugerido, se pueden desplegar en tres dimensiones distintas, que además estarían íntimamente relacionadas con los tres conceptos de Filosofía de Xavier Zubiri, rescatados por el propio Ellacuría en una conferencia, "Filosofía y Política" ${ }^{29}$, en la Universidad Pontificia de Comillas:

26 Cfr. I. Ellacuría, “El sujeto...” 313. Sobre esto, reconoce Ellacuría, más adelante, compartir la definición de posibilidades elaborada por E. BLOCH en su obra Principio esperanza.

27 Cf. I. Ellacuría, "Función liberadora de la filosofía”, en Veinte años de historia en El Salvador (1969-1989) 1 (UCA editores, San Salvador 1991) 101. Impreso originalmente en ECA 435-436 (1985) 45-64.

28 I. Ellacuría, "Hacia una fundamentación filosófica del método teológico latinoamericano", en ECA 322-323 (1975) 419.

29 I. Ellacuría, "Filosofía y política", en Veinte años de historia en El Salvador (19691989 I (UCA editores, San Salvador 1991) 56. Impreso originalmente en ECA 284 
"En el curso de la historia nos encontramos con tres conceptos distintos de la filosofía, que emergen, en última instancia, de tres dimensiones del hombre:

$1^{\circ}$ La filosofía como un «saber» de las cosas.

$2^{\circ}$ La filosofía como una «dirección» para el mundo y la vida.

$3^{\circ}$ La filosofía como una «forma de vida», y, por tanto como algo que acontece.

En realidad, estos tres concepciones de la filosofía, que corresponden a tres concepciones distintas de la inteligencia [teórica, práctica e histórica], conducen a tres formas absolutamente distintas de intelectualidad"30.

En lo relativo a que la filosofía sea un saber acerca de las cosas, Ellacuría abre paso a la filosofía como contemplación, por sobre lo operativo, o por sobre la praxis transformadora. Aunque nos comenta que también es cierto que la historia nos ha mostrado que los filósofos de la antigüedad, con una erudición impecable, han participado de la orientación de la polis, convirtiendo también a este aspecto de la filosofía en una forma imprescindible para la configuración de la sociedad ${ }^{31}$. Respecto del comprender la filosofía como dirección para el mundo y la vida, aclarará que es un concepto "ya [...] formalmente político. Se trataría de un saber, pero un saber rector del mundo y de la vida” ${ }^{32}$. Pues las cosas, más allá de entenderlas como un objeto alejado de nosotros, de observarlas como cosas en sí, son en cuanto entran en nuestra vida, se relacionan con ella y son públicas o, de otro modo, políticas ${ }^{33}$. Finalmente, en lo relativo al concepto de filosofía como una forma de vida, señala que es evidente que sea también esencialmente político; pues lo histórico, como dinamismo de la vida humana, permite que la filosofía pueda ser plenamente ella, considerando todas aquellas situaciones en las que la vida se instala, y que con la inteligencia dan ocasión al filosofar mismo.

(1972). La triple definición de filosofía es Teoría o la pregunta sobre qué son las cosas, Práctica, dirección para la vida y el mundo, e Histórica, filosofía como modo de vida o acontecer.

30 X. Zubiri, Naturaleza, historia y Dios (Alianza y Fundación Zubiri, Madrid 1974) 110.

31 I. Ellacuría, "Filosofía y política" 56.

32 I. Ellacuría, "Filosofía y política" 56.

33 I. Ellacuría, "Filosofía y política" 57. 
En efecto, podemos ver que la filosofía y el ser humano están implicados vitalmente, pero aquella implicación responde a una triple dimensión del ser humano, o más bien de la inteligencia, que lo conducen a otras tres formas distintas de intelectualidad, que se ejercitarán dependiendo de cada época y persona, y jugándose, al fin, el para qué de la inteligencia y de la vida ${ }^{34}$.

Filosofía como saber desplegará el sentido predominantemente contemplativo de la inteligencia, una inteligencia teórica: "La inteligencia es para saber, y el saber es un valor en sí que da el supremo valor a quien se dedica a él. De este saber se desprenderán forzosamente influjos, incluso sobre la configuración de la ciudad y, desde luego, de la vida de los ciudadanos" 35 . La filosofía como dirección del mundo y de la vida pertenece a un sentido activo y rector de la inteligencia, una inteligencia práctica, una actividad transformadora, una inteligencia activa que es techné, o técnica, en sentido aristotélico. No se trataría tanto de un saber cerrado sobre sí capaz de dirigir la acción una vez lograda la teoría, sino más bien de un dirigir sabio, en el sentido de que solo en la dirección activa se encontraría el campo y las direcciones del saber, al tiempo que la dirección no podría ser realmente dirección sin el debido saber ${ }^{36}$. La filosofía como forma de vida, entonces, corresponde a un sentido de la inteligencia como inteligencia histórica; que a su vez es una inteligencia situada, "es decir una inteligencia que sabe que no puede entrar al fondo de sí misma más que situadamente y pretendiendo entrar al fondo de la situación tomada en su totalidad" 37 .

La inteligencia, sin más, cobra entonces una vital importancia, pues además de lo ya planteado, Ellacuría ha heredado de Zubiri una versión que, si bien puede expresarse de las tres maneras que hemos descrito, se relaciona directamente con el sentir, y esto, de una manera tal, que solo en su estricta unidad puede aprehender la realidad. El inteligir es, entonces, un modo de sentir y el sentir un modo de inteligir ${ }^{38}$. Con ello además se negaría toda posibilidad de dualidad como la que sobrepone

\footnotetext{
I. Ellacuría, "Filosofía y política" 59.

I. Ellacuría, "Filosofía y política” 59.

Cf. I. Ellacuría, "Filosofía y política" 59.

I. Ellacuría, "Filosofía y política" 59.

38 Cf. I. Ellacuría, "La nueva obra de Zubiri: inteligencia sentiente", en Escritos filosóficos III (UCA, San Salvador 2001) 310. Impreso originalmente en Razón y fe 203/995 (1981) 126-139.
} 
(o antepone) a una de la otra, separando y estratificando grados de acceso a la realidad. Que la sensibilidad sea el acceso a la realidad verdadera, no es puesto en $d u d a$ como lo hicieron tantos racionalistas modernos; y es que la cuestión para Zubiri y Ellacuría es clara: que la aprehensión de la realidad solo puede ser inteligida y pensada si es sentida, cuestión que, además, hace que la formalidad de la realidad esté realmente presente, y no solo conceda la complicación del contenido (como lo hicieron los empiristas), pues esta nos muestra "los distintos y complejos modos de inteligir"39, que son modos propios y no ya un de suyo vacío y abstracto.

Es por ello que podemos relacionar la triple definición de filosofía con tres modos distintos de inteligir, pues no existe un único modo de acceso a las cosas, como intelección sentiente, dada la diferencia de las funciones de los órganos que tiene nuestro cuerpo humano. En efecto, nos recuerda Ellacuría que

"[...] no solo ofrece contenidos propios (colores, sabores, frío, calor, etc.) sino modulaciones propias de la formalidad de realidad. Me presenta la realidad de modo distinto (ante mí, en, hacia, etc.). De suerte que si se carece radicalmente de un sentido, se carece de un modo específico de intelección, y no solo de un contenido específico" ${ }^{40}$.

Y es a través de estos modos desde donde surge la mayor riqueza de aprehensión de la realidad, pues a través de ellos se pone en ejercicio lo que Ellacuría llama realidad verdadera, que abarca

"[...] la trascendentalidad de la realidad, la respectividad de lo real y la actualización de la respectividad mundanal que es el ser. Por el sentir intelectivo no solo estamos abiertos a la realidad y al ser, sino impulsados irresistiblemente a navegar sin fin por todo tipo de realidad y toda forma de ser" ${ }^{\prime 4}$.

La filosofía, entendida desde estos autores, entonces, se sitúa en la realidad de la manera más omnicomprensiva que puede alcanzar la inteligencia humana, cuestión fundamental para la constitución de cualquier empresa filosóficas y en especial para una que, concretamente, no quiere dejar de lado ningún mundo de vida.

39 I. Ellacuría, "Filosofía y política" 60.

40 I. Ellacuría, "Filosofía y política” 60.

41 I. Ellacuría, "La superación del reduccionismo idealista en Zubiri”, en ECA 477 (1988) 649. 
De estos tres modos de entender lo que es la filosofía, se pueden comprender con mayor precisión las dimensiones intelectivas, éticas y práxicas que hemos comentado anteriormente. Estas tríadas se ejercitarán dependiendo, igualmente, de cada época (altura de los tiempos), de la persona (sujeto histórico), y jugándose, al fin, el para qué de la inteligencia y de la vida (la liberación) ${ }^{42}$.

Sin embargo a estas dimensiones Jon Sobrino ha incorporado una cuarta dimensión: La dimensión de gracia o de dejarse cargar por la realidad, la cual -creemos- se vuelve fundamental para comprender la obra ellacuriana toda.

\section{DEJARSE CARGAR POR LA REALIDAD}

La idea de dejarse cargar por la realidad, presentada por Jon Sobrino, es, según el teólogo, fruto del diálogo e interacción con Ignacio Ellacuría. Sobrino lo explica después de la muerte de su compañero como propio del pensamiento ellacuriano, pues emerge desde el impacto que le produjo ver en Ellacuría un énfasis por encargarse de la realidad, pero aún más por tener que cargar con ella. Sobre esto escribe:

"Viniendo de otros lares, suponía una novedad total escuchar -y percibirlo en la persona de Ellacuría- que la inteligencia «no se ha dado al hombre para evadirse de sus compromisos reales, sino para cargar sobre sí con lo que son realmente las cosas y con lo que realmente exigen». Esto quiere decir que no se puede inteligir adecuadamente la realidad sin cargar con lo oneroso de ella, lo cual, pienso, no es muy tomado en cuenta hasta el día de hoy"³.

A esto agrega -incorporando el suelo nutricio desde el que reflexiona nuestro autor- que Ellacuría se hizo cargo de la realidad como pueblo crucificado, que con distinta historia de crucifixión, pero como siempre, es despojado de todo, tal como el siervo de Yahvé, hasta de la vida ${ }^{44}$.

El pueblo crucificado, que en Ellacuría se representa en las mayorías populares, se explica desde su adjetivo; pues se vivifica en él la vida de

42 I. Ellacuría, "Filosofía y política” 59.

43 J. Sobrino, "'El pueblo crucificado' y 'la civilización de la pobreza'. 'El hacerse cargo de la realidad' de Ignacio Ellacuría”, en J. A. Nicolás y H. SAmour, Historia, ética y ciencia. El impulso crítico de la filosofía de Zubiri (Comares, Granada 2007) 431.

44 J. Sobrino, “'El pueblo crucificado'...” 432. 
cruz. Tanto Ellacuría como Sobrino se caracterizaron por pertenecer a una corriente de teólogos llamados de la liberación, quienes dedicaban sus reflexiones sobre Dios haciendo principal énfasis a la figura de Jesús de Nazareth, y desde una apuesta radical por los pobres, como opción preferencial $^{45}$. La cruz representa para ellos un símbolo de dolor y sufrimiento en los que Jesús de Nazareth padece la muerte, tras injusta sentencia, y la dificultad de una vida en pobreza, discriminación y tentaciones, entregada hacia la transformación de la misma. Pero también como signo de esperanza, pues para estos teólogos cristianos es Dios mismo el que se abaja, y se encarga de la realidad, para asegurar a los pobres una buena noticia. Desde aquí, es necesaria su muerte, pero solo entendida como una necesidad histórica, como una realidad naturalizada y no natural ${ }^{46}$.

Es así como Ellacuría nos exhibe la imagen de Jesús de Nazareth, humillado hasta la muerte, en analogía al pueblo crucificado, las mayorías, que hoy viven esa muerte, como el resultado de acciones históricas, que se le presentan como el único todo real que le toca vivir. Es precisamente esta paradoja, de vida y muerte, de ser y nada, la que resalta Sobrino de la filosofía de nuestro pensador; pues cuando Ellacuría comenta de Martín Heidegger la cuestión de su famosa interrogante: por qué hay más bien ente que nada, él plantea que debió haberse preguntado "por qué no hay nada -no ser, no realidad, no verdad, etc.- en vez de ente" ${ }^{47}$. Mas aquella negatividad no es según Sobrino cualquier teoría filosófica de contrarios y leyes abstractas explicadas en algún macrosujeto, sino que, la profundidad de estas proposiciones, solo se puede revelar desde aquel pueblo crucificado que

"[vive] una muerte histórica que toma la forma de crucifixión, asesinato, activa privación histórica de la vida, lenta o rápidamente. A esa muerte, producto de la injusticia, acompaña la crueldad, el desprecio y, por otra parte, el encubrimiento. A esto suelo añadir que al pueblo crucificado, además, se le niega palabra y hasta nombre, y con ello se le niega existencia. El pueblo crucificado no 'es', y el mundo de abun-

45 Cf. I. Ellacuría, Mi opción preferencial por los pobres (Nueva Utopía, Madrid 2009).

46 Cf., I. Ellacuría, "El pueblo crucificado. Ensayo de soteriología histórica”, en Cruz y Resurrección. Presencia y anuncio de una iglesia nueva (Soto, México 1978) 58.

47 Cf. . I. Ellacuría, "Función liberadora...” 101. 
dancia impide o dificulta que 'llegue a ser'. Así puede desentenderse - sin mala conciencia- de lo que ocurre a esas mayorías" ${ }^{38}$.

No es nihilismo, empero, lo que anima a estos vascos, sino la esperanza que nace de la cruz como una segunda oportunidad. Pues insistirán que luz y esperanza tienen y pueden ofrecer los pueblos periféricos al mundo. La salvación, para Ellacuría, viene desde abajo, desde los que no tienen nada, nada que temer ni perder. Viene desde los que siempre han caminado cargando la cruz impuesta por la realidad. Siempre, como nos recalca Jon Sobrino, aunque con distintos rostros, que siguen presenciando diferencias extremas y escandalosas, y en ella, a la muerte ${ }^{49}$. Con todo, a pesar de la muerte -insistirá Sobrino- ellos no mueren; por lo contrario, se levantan cotidianamente y soportan, trabajan, esperan. De esto trata el dejarse cargar por la realidad. Pues el pueblo crucificado carga con nosotros, "y lo hace de diversas formas: nos da nuevos ojos para ver, nos da manos nuevas para trabajar, nos da espaldas amplias para soportar. Y nos da esperanza" ${ }^{50}$.

En Ellacuría, el hacerse cargo de la realidad tiene entonces también un elemento de gracia ${ }^{51}$. Pues quien se hace cargo, iluminado por el propio pueblo sufriente, amenazado y humillado, responde y corresponde, se deja cargar por la realidad.

Aquí hemos llegado a una cuestión clave en el pensamiento de Ignacio Ellacuría, y es que, el que haya sido sacerdote (y religioso), fue marcando una visión particular de ver las cosas, teñida por la imagen de Cristo crucificado y resucitado. Que haya experimentado dentro de las obediencias de su Congregación una experiencia encarnada de la fe, lo obligó a distanciar su mente de libros y dogmas y ver participativamente una realidad que estaba siendo (seinde), y haciendo, de una determinada

48 J. Sobrino, “'El pueblo crucificado'...” 433.

49 Cf. J. Sobrino, “'El pueblo crucificado'...” 437.

50 J. Sobrino, “'El pueblo crucificado'...” 439.

51 Sobre la "graciosidad" del pueblo nos recuerda Sobrino las siguiente palabras de Enrique Gómez García: “La 'graciosidad' que encierra la realidad, y que solo el hombre con espíritu es capaz de percibir como la presencia providente de Dios en su creación, encuentra su desarrollo más explícito en la comprensión zubiriana del poder de lo real, que propicia la dimensión de fundamentalidad”. En E. Gómez GarCía, "De la 'espiritualidad de lo real' a la 'filosofía de la realidad'. Aportes de Xavier Zubiri a la espiritualidad de la liberación”, en Revista de Espiritualidad 63 (2004) 548 ss. 
forma. Desde aquí podemos decir que no fue Zubiri y Ortega, aunque también; que no fue Hegel y Marx, aunque también; que no fue Rahner y Sobrino, o monseñor Romero, aunque también, sino que fue su formación religiosa, como discípulo de Jesús, la que hizo madurar una sensibilidad que no solo le fue adiestrando en su propio conocimiento interno, de discernimiento continuo de su vida como es fundamental para los ignacianos, sino también circunscrito en entrega generosa, dispuesta y abierta a la realidad. Fue formado para ser seguidor de Jesús de Nazareth, mártir de los pobres, pero la más profunda lección se la dio el propio pueblo crucificado. Ellacuría fue asumiendo una fe lúcida (examinadora), en la que se empapó de la vida salvadoreña, con las dificultades que le toca vivir a sus ciudadanos, por ello es que la idea de Dejarse cargar por la realidad, que le propuso Sobrino a su desafío de la realidad histórica, fue bien aceptado; pues, aunque no lo abordó con esas palabras en sus artículos ${ }^{52}$, estaba ya expuesta en la imagen con la que ejemplificaba muchos de sus escritos, sobre todo en sus artículos teológicos. En uno de estos lo presenta así:

"Es fácil ver a los oprimidos y necesitados como aquellos que requieren ser salvados y liberados, pero no lo es el verlos como salvadores y liberadores [...]. Resulte o no escandaloso proponer la pasión y la crucifixión de Jesús y del pueblo como centrales para la salvación del hombre, la pasión de Jesús, precisamente por su propia inverisimilitud salvífica, ilumina la inverisimilitud salvación de la crucifixión del pueblo mientras que esta evita una lectura ingenua o ideologizada de aquella" 53 .

Para Ellacuría, es el pueblo sufriente, entonces, el lugar de salvación; desde él emana la vida y la esperanza. El pueblo sufriente, tal como - dirá- el siervo de Yahvé para los cristianos, es la kénosis actual del Dios que muestra a los hombres y mujeres la verdad.

Siervo de Yahvés4 es la figura bíblica que utilizó Ignacio para mostrar, tal como lo entendieron las primeras comunidades cristianas, la muerte de Jesús; como también para mostrar la muerte de nuestros pueblos.

52 Cf. J. Sobrino, “'El Ellacuría olvidado'. Lo que no se puede dilapidar”, en J. A. Senent de Frutos y J. Mora Galiana, Ignacio Ellacuría 20 años después. Actas del Congreso Internacional (Instituto Andaluz de Administración Pública, Sevilla 2009) 319-342.

53 I. Ellacuría, “El pueblo crucificado...” 121.

54 Cf. I. Ellacuría, "El pueblo crucificado...” 125 ss. 
Con ella ilustra además esa unión y pacto entre Dios y la Historia. Así se describe en Isaías (el segundo Isaías) donde se revela a un siervo elegido que trae luz y poder a las naciones, y que además, les trae el perdón de sus pecados. Ahora bien, aunque paradójico, aquel elegido lejos estaba del uno y del otro, del poder y del pecado. Sin embargo así, sufriente y humillado, cumplió su destino, el que con él, Dios mismo, incluso, estaba asumiendo. Por ello, el siervo acepta este plan injusto, y salva, a través de su sufrimiento, a quienes son los propios causantes de él.

Después de esto, siervo de Yahvé será todo aquel que enfrente este destino: el de cargar injustamente con los pecados de los seres humanos. Por estas razones, Ellacuría actualiza esa idea diciendo que son las mayorías populares (con sus diferentes rostros), que aunque no sepan universitariamente lo que significa Jesús o el Reino, hoy son Juez; aunque no formulen juicio teológico, por oposición posibilitante que da salvación a lo que se hace mal, son exigencia posibilitadora, universal y sentenciadora de la propia historia.

El pueblo crucificado, entonces, es víctima del pecado y salvación del mundo, aunque Ellacuría nos agrega que esta es solo una primera etapa, pues queda otra: "no hay salvación por el mero hecho de la crucifixión y de la muerte: solo un pueblo que vive, porque ha resucitado de la muerte que se le ha infligido, es el que puede salvar al mundo" ${ }_{55}$. Así lo podemos leer también en el término del Cuarto poema al siervo de Dios en el mismo Isaías, en donde se muestra la respuesta a la alianza hecha entre Dios y su siervo:

"Después de una vida de amarguras verá la luz, comprenderá su destino. Mi siervo, el justo, traerá a muchos la salvación cargando con las culpas de ellos. Por eso, le daré un puesto de honor entre los grandes, y con los poderosos participará del triunfo, por haberse entregado a la muerte y haber compartido la suerte de los pecadores. Pues él cargó con los pecados de muchos e intercedió por los pecadores" ${ }^{\text {"56 }}$.

Y de ello sigue "canta de alegría, rompe a cantar". ¿Qué significa ese canto alegre, que es salvífico? Para dar respuesta es indispensable explicitar la característica central del pobre que hemos venido esbozando como sujeto de liberación: En Ellacuría, se trata del pobre con espíritu; del pobre que es capaz de levantarse a pesar del dolor, de aguantar, que

55 I. Ellacuría, "El pueblo crucificado...” 129.

56 ISAÍAS 53,11-12. 
no busca acomodarse personalmente en el banquete de este mundo, de lo contrario, que se compromete con la desaparición de las condiciones reales de despojo violento. Desde aquí, el pobre con espíritu, y el pueblo con espíritu es a quienes debemos dejarnos cargar.

Leemos entonces que el pobre no es a quien le ha ido mal en el juego del quién gana más, que caracteriza nuestros días; sino a aquel que alejado de estas prácticas y del sistema que ha alzado al Capital como único dios, es capaz de tener esperanza en que la realidad abierta tome nuevos rumbos, con trabajo y solidaridad. Y decimos solidaridad, porque para Ellacuría era fundamental la labor de la comunidad, de las mayorías populares, haciéndose cargo de la realidad, para lanzar la historia hacia otra dirección, mas ahora sabemos que no se trata solo de mayorías populares, tan solo por ser populares, sino porque ellas son ejemplo de lucha y esperanza. Se trataría, según nuestro autor, de comunidades que quieren anunciar y realizar el Reino de Dios a todos los hombres y mujeres de la tierra. Se trataría, además, de una organización política, del pueblo que hace Iglesia ${ }^{57}$.

\section{CONCLUSIONES}

La relación indisoluble de Dios con su pueblo se manifiesta en la teología de nuestro autor claramente como aquel canto de esperanza. Empero, la cuestión de Dios y el pacto, también están presente, como nos dice Sobrino, de manera detallada en su filosofía ${ }^{58}$. Fueron variadas las versiones de una propuesta filosófica en la que se arrojó al tema de la liberación; pero sobre todo como posibilitante de la realización de un mundo que pudiera garantizar la existencia verdadera (no alienada) y digna, de todos los seres humanos, y compatibles con la naturaleza. Y es que, su lugar de enunciación, San Salvador, la Compañía de Jesús, y el momento histórico que le tocó vivir en las décadas previas a su muerte, le mostraron a Ellacuría aquellas cuestiones que debían tomar urgencia en sus reflexiones; de este modo, haciéndose cargo de su realidad histórica, él asume el desafío de cargar con ella y encargarse positivamente

I. ElLACURÍA, Mi opción preferencial por los pobres (Editorial Nueva Utopía, Madrid 2009) 137.

58 J. Sobrino, “Ignacio Ellacuría, el hombre y el cristiano", en I. Ellacuría, J. Sobrino, R. CARDENAL, Ignacio Ellacuría, el hombre el pensador y el cristiano (EGA, Bilbao 1994) 53. 
de ella; pero esto, con los pobres de El Salvador, bebiendo de ellos su obstinada capacidad de lucha diaria y alegría, dejándose cargar por ellos.

Hasta aquí hemos querido mostrar cómo esa actividad inexorable de cargar sobre los hombros nuestra realidad se puede convertir en desafíos de toda ética, y en especial de una ética de la liberación; es decir, de aquella que, a través de una praxis transformadora, vaya permitiendo la posibilitación de un lugar futurible que troque los llantos en cantos de alegría triunfal. Pensar esta realidad para todos los seres humanos del planeta significa asumir una tarea radical, que en otros escritos, Ellacuría reclama a través de un giro antropológico para la construcción de una Civilización de la Pobreza ${ }^{59}$. Esta alternativa comporta una suerte de crítica al estado de desarrollo establecido en nuestras sociedades, pero sobre todo, ofrece la posibilidad de lanzar la historia hacia otra dirección, desde la convicción de que ella misma es realidad siempre abierta. Esta labor, tal como se ha insinuado en este escrito, no es misión de un pensamiento ideologizado, sino precisamente lo contrario, desvelamiento de la verdad de la realidad, desde un filosofar auténtico.

59 I. Ellacuría, "Utopía y profetismo desde América Latina; un ensayo concreto de soteriología histórica”, en Revista Latinoamericana de Teología 17(1989) 141-184. Reimpreso en I. Ellacuría. - J. Sobrino (Comps.), Mysterium Liberationis 1 (Trotta - Fundación Xavier Zubiri, Madrid 1990) 393-442. 
